\section{Non Cross Reacting Antigen}

S. Holdenrieder ${ }^{1}$ und P. Stieber ${ }^{2}$

${ }^{1}$ Institut für Laboratoriumsmedizin, Deutsches Herzzentrum München, Klinik an der Technischen Universität München, München, Deutschland

${ }^{2}$ Institut für Laboratoriumsmedizin, Klinikum der Universität München (LMU), München, Deutschland

\section{$\operatorname{Synonym(e)~NCA~}$}

Englischer Begriff non-specific non-reacting antigen

Definition Das „non-specific non-reacting antigen“ ist ein Mitglied der CEA-Familie ( $\triangleright$ Carcinoembryonales Antigen).

Struktur Bisher wurden 29 kodierende Gene der CEAFamilie beschrieben. 18 verschiedene Proteine werden exprimiert, wovon 7 der CEA-Subgruppe und 11 der „pregnancyspecific glycoprotein (PSG)“-Subgruppe angehören.

Das „,non-specific non-reacting antigen“ (NCA) ist zusammen mit dem CEA, dem biliären Glykoprotein (BGP) und den sogenannten „CEA gene family members“ (CGM) 1, 2, 6 und 7 ein Mitglied der Zellmembran-assoziierten CEA-Subgruppe.

Synthese - Verteilung - Abbau - Elimination Das „nonspecific non-reacting antigen" (NCA) zeigt ein weniger selektives Expressionsmuster als CEA und wird von einer Reihe normaler Epithelien des Gastrointestinaltrakts, Urogenitaltrakts, der gynäkologischen Organe sowie in Granulozyten und Monozyten gebildet.
Funktion - Pathophysiologie Das ,non-specific nonreacting antigen" (NCA) hat ähnlich wie die anderen CEASubgruppen Mitglieder zelladhärierende Eigenschaften.

Eine erhöhte Expression des NCA findet sich bei verschiedenen malignen Tumoren, so beim kolorektalen Karzinom, Magenkarzinom, Lungenkarzinom, Ovarialkarzinom, Endometriumkarzinom, Mammakarzinom und bei der akuten lymphoblastischen Leukämie.

Untersuchungsmaterial - Entnahmebedingungen Serum, Plasma.

Analytik Enzymimmunoassay (EIA), Immunradiometrischer Assay (IRMA).

Indikation Diagnostik und Verlaufskontrolle von Adenokarzinomen (durch CEA ersetzt).

Interpretation Aufgrund des im Vergleich zu CEA weniger selektiven Expressionsmusters wird in Diagnostik und Verlaufskontrolle von Tumorerkrankungen die Bestimmung des „non-specific non-reacting antigen“ (NCA) durch das spezifischere CEA ersetzt.

Diagnostische Wertigkeit Diagnostik und Verlaufskontrolle von Adenokarzinomen (durch CEA ersetzt).

\section{Literatur}

Hammarström S (1999) The carcinoembryonic antigen (CEA) family: structures, suggested functions and expression in normal and malignant tissues. Semin Cancer Biol 9:67-81 